\title{
NORMA FAKE LAW: A NÃO FIXAÇÃO DE PRAZO PARA A INSCRIÇÃO NO CADASTRO AMBIENTAL RURAL
}

\author{
João Hélio Ferreira Pes ${ }^{1}$; Micheli Capuano Irigaray²
}

\section{RESUMO}

Este artigo analisa a incidência do fenômeno fake law na norma que alterou o Código Florestal para determinar a obrigatoriedade da inscrição de imóveis no Cadastro Ambiental Rural sem a fixação do prazo. O objetivo principal verificar se o prazo indeterminado para cadastrar imóveis rurais caracteriza uma fake Law no ordenamento jurídico brasileiro? Para enfrentar o problema proposto foi utilizada a metodologia sistêmico-complexa, com uma visão multidisciplinar, método dedutivo com o auxílio de consulta bibliográfica e documental. A partir de elementos que constituem a caracterização de fake law é efetuada a análise do texto normativo relativo a não exigência de prazo para a inscrição de imóveis no Cadastro Ambiental Rural. A conclusão é de que política pública de controle e gestão ambiental deve conter instrumentos eficazes de tutela administrativa efetiva, com prazo para regularização e inserção de informações sobre imóveis rurais no sistema do cadastro ambiental rural - CAR.

Palavras-chave: Cadastro ambiental rural, Fake law, informação ambiental.

Eixo Temático: Direitos, Políticas Públicas e Diversidade (DPD).

\section{INTRODUÇÃO}

O cadastro ambiental rural apresenta-se como política pública de controle e gestão ambiental, tendo a informação como instrumento fundamental para tomada de decisões e ampliação de ações dentro da política pública de proteção ambiental. Assim pressupõe-se que pela relevância do tema abordado, o poder público atue através de uma tutela administrativa efetiva, na proteção ambiental, controle e gestão de informações dos imóveis e atividades desenvolvidas na área rural.

\footnotetext{
1 Universidade Franciscana ( UFN), Santa Maria - RS, Brasil. joaohelio@ufn.edu.br.

2 Universidade de Santa Cruz (UNISC), michelicapuanoirigaray@gmail.com.
} 
Para a implementação de uma tutela administrativa efetiva, destaca-se a necessidade de instrumentos de controle, como a fixação de prazo adequado para implementação das informações referentes aos imóveis rurais, na composição de dados do Sistema Nacional de Informações sobre Meio Ambiente - SINIMA.

Assim, normas jurídicas introduzidas no ordenamento jurídico brasileiro com a intenção de apenas agradar setores da sociedade ou parcelas da população, sem a mínima preocupação com a sua eficácia, não convergem para uma tutela administrativa efetiva. Nesse contexto destaca-se a prática da elite política, dos governantes e legisladores brasileiros, com a edição de medidas provisórias, aprovação de leis e de outras espécies normativas que tem efeito meramente fake law, ou seja, norma juridicamente falsa, no sentido de constar em seus comandos normativos algo sem qualquer eficácia, além de enganar os destinatários quanto ao 'dever ser' ou 'ser', próprios das normas jurídicas.

Com esse panorama, o objetivo deste artigo é analisar a incidência de efeito fake law na norma que alterou o Código Florestal, Medida Provisória nº 884, de 14 de junho de 2019, convertida na Lei $n \cong$ 13.887/2019, para incluir regra que torna facultativa a inscrição antes obrigatória no Cadastro Ambiental Rural - CAR.

Para desenvolver o tema e apresentar uma resposta adequada foi utilizado o método dedutivo a partir de elementos que caracterizam o fenômeno denominado fake lawe a sua incidência na medida provisória adotada pelo Chefe do Executivo brasileiro, posteriormente, convertida em lei. É utilizada, também, consulta bibliográfica e documental com a análise de textos normativos.

O artigo está dividido em duas partes, sendo que a primeira aborda a relevância do Cadastro Ambiental Rural - CAR. A segunda parte menciona alguns elementos constitutivos de uma breve definição para o fenômeno fake law para analisar se a alteração normativa no Código Florestal sobre o Cadastro Ambiental Rural pode ser identificada como fake law.

O resultado apresentado no final é de que o cadastro ambiental rural, como política pública de controle e gestão ambiental, deve conter instrumentos eficazes de tutela administrativa efetiva, assim como o prazo para regularização e inserção de informações sobre imóveis rurais no sistema nacional de informações ambientais, 
em atendimento ao princípio da informação, transparência e controle social de políticas públicas.

\section{A RELEVÂNCIA DO CADASTRO AMBIENTAL RURAL}

O Cadastro Ambiental Rural - CAR foi instituído pela lei 12.651 de 2012, legislação que dispõe sobre a proteção da vegetação nativa e, também, conhecida como Código Florestal Brasileiro. No Capítulo VI, os artigos 29 e 30 do Código Florestal fixam as regras, conceito e finalidade do novo e importante instrumento de proteção ambiental fixado no Ordenamento Jurídico Brasileiro, a partir das alterações do Código Florestal realizadas em 2012. O Cadastro Ambiental Rural é um registro público eletrônico georreferenciado das informações ambientais dos imóveis rurais e urbanos que tenham destinação rural, ou seja, de todas as propriedades e posses rurais do país (BRASIL, 2012).

Inegavelmente, o Cadastro Ambiental Rural é um instrumento relevante para o Sistema Nacional de Informação sobre Meio Ambiente - SINIMA, com a finalidade de promover a identificação e integração das informações ambientais das propriedades e posses rurais, compondo base de dados para subsidiar o planejamento ambiental, o controle e monitoramento de espaços ambientais que devem ser conservados e, ainda, combater ao desmatamento e auxiliar nos processos de regularização ambiental.

O Sistema Nacional de Cadastro Ambiental Rural - SICAR, também, apresenta-se como banco de dados que necessita das informações coletadas pelo Cadastro Ambiental Rural - CAR, para o gerenciamento e integração de todos os entes federativos, visando cadastrar e controlar as informações dos imóveis rurais, referentes a seu perímetro e localização, assim como aos remanescentes e vegetação nativa, áreas e interesse social e áreas de utilidade pública. Essas identificações visam também verificar as Áreas de Preservação Permanente e Áreas de Uso Restrito consolidadas, assim como às Áreas de Reserva Legal (BRASIL, 2021).

Esse monitoramento apresenta-se como fator relevante para a manutenção, recomposição, regeneração e compensação de áreas degradas, além de ser um 
instrumento de verificação de supressão da vegetação nativa e da cobertura vegetal nas Áreas de Preservação Permanente ${ }^{3}$, de Uso Restrito e de Reserva Legal ${ }^{4}$, no interior dos imóveis rurais. Nesse contexto o CAR tem função preponderante como ação e instrumento de gestão ambiental, permitindo um planejamento ambiental e econômico do uso do solo e de conservação ambiental no território nacional (BRASIL, 2021).

Nesse contexto o CAR apresenta-se como ferramenta essencial a manutenção da base de dados do Sistema Nacional de informações Ambientais, assim como do Sistema Nacional de Cadastro Ambiental Rural, convertendo-se em informação de natureza pública sobre a regularização ambiental dos imóveis rurais em território nacional, essencial a melhoria da qualidade de vida e bem-estar de toda a coletividade.

Assim, a informação ambiental é um dos elementos relevantes e um dos pressupostos indispensáveis ao exercício da cidadania ambiental no Direito Brasileiro. Com essa preocupação e com a devida valorização à informação ambiental, Jose Rubens Morato Leite e Patryck de Araújo Ayala (2004, p. 330) afirmam: "Assim como a educação ambiental, a informação a questões relativas ao meio ambienta também é um pressuposto para que a participação popular na defesa do meio ambiente seja efetivada". Portanto, a instituição de um cadastro ambiental para sistematizar todos os dados sobre os imóveis rurais e os espaços que devem ter uma proteção especial é fundamental para a política de preservação ambiental.

Ademais, não se pode olvidar que a informação ambiental é um direito que está interrelacionado com outros direitos e outros princípios como o da publicidade, transparência e participação. Assim, é imprescindível a garantia do exercício do direito à informação para que seja observado o Princípio da Participação

\footnotetext{
${ }^{3}$ Área de Preservação Permanente - APP: área protegida, coberta ou não por vegetação nativa, com a função ambiental de preservar os recursos hídricos, a paisagem, a estabilidade geológica e a biodiversidade, facilitar o fluxo gênico de fauna e flora, proteger o solo e assegurar o bem-estar das populações humanas, conforme artigo $3^{0}$, inciso II do Código Florestal Brasileiro (BRASIL, 2012).

${ }^{4}$ Reserva Legal: área localizada no interior de uma propriedade ou posse rural, delimitada nos termos do art. 12, com a função de assegurar o uso econômico de modo sustentável dos recursos naturais do imóvel rural, auxiliar a conservação e a reabilitação dos processos ecológicos e promover a conservação da biodiversidade, bem como o abrigo e a proteção de fauna silvestre e da flora nativa, conforme artigo $3^{0}$, inciso III do Código Florestal Brasileiro (BRASIL, 2012).
} 
Democrática como princípio constitutivo do direito ambiental. Nesse sentido, é correta a frase concebida por Paulo Afonso Leme Machado (2013, p. 65): "Uns princípios serão constitutivos do próprio Direito Ambiental e outros princípios serão instrumentais, destinando-se a viabilizar os princípios constitutivos".

Assim a informação ambiental interliga-se com o direito fundamental ao desenvolvimento nacional sustentável, de acordo com os valores plasmados no texto constitucional, de legitimidade das políticas públicas adotadas pelo Estado, visando fundamentalmente a dignidade da pessoa humana, mediante a promoção da melhoria de vida e do bem-estar da população, no amparo de um desenvolvimento sustentável, no exercício dos direitos humanos e liberdades fundamentais (SCHIER, 2020, p. 13).

Nesse contexto a integração dos Cadastros Ambientais Rurais de todas as Unidades da Federação apresenta-se como fator fundamental para base de dados do Sistema de Cadastro Ambiental Rural - SICAR, previsto no Decreto n 7.830 , de 17 de outubro de 2012, que regulamentou o Cadastro Ambiental Rural - CAR. Os proprietários ou os possuidores de imóveis rurais que tem obrigações pendentes quanto à regularização de seus imóveis para cumprir com os parâmetros legais de proteção às áreas especiais, ou seja, com passivo ambiental relativo às Áreas de Preservação Permanente, de Reserva Legal e de uso restrito poderão proceder à regularização ambiental mediante adesão aos Programas de Regularização Ambiental dos Estados e do Distrito Federal - PRA desde que estejam inscritos no Cadastro Ambiental Rural - CAR, tudo conforme previsto no Decreto $n^{0} 7.830$, de 17 de outubro de 2012 e no Decreto no 8.235, de 5 de maio de 2014 .

A obrigatoriedade da inscrição de todos os imóveis rurais, em âmbito nacional, no Cadastro Ambiental Rural está fixada, de forma clara, no caput do artigo 29 da lei 12.651 de 2012. Tal regra, inequivocamente, justifica-se pela significância que esse cadastro tem para a proteção dos bens ambientais naturais localizados nos mais diversos biomas de todo o território nacional. Nesse sentido, vale registrar a manifestação de reconhecimento da importância do Cadastro Ambiental Rural pelo Professor Cristiano Pacheco de Deus Mundim (2016, p. 165): "o CAR foi criado com 
um objetivo maior, o controle e gerenciamento em um banco de dados nacional, das áreas de proteção especial".

Portanto, apresenta-se como fundamental a implementação, dentro de prazo estabelecido, da ampliação do sistema do Cadastro Ambiental Rural, como ação de tutela administrativa efetiva, na conservação, preservação e gerenciamento ambiental no país.

Para além de um tempo/espaço de desencaixes (GIDDENS, 1991, p. 29) emerge a necessidade de compatibilização e definição de prazo para universalização da implementação do sistema CAR, em atenção a Instrução Normativa n. 2, de 5 de maio de 2014, que dispõe sobre os procedimentos para a integração, execução e compatibilização do Sistema de Cadastro Ambiental Rural — SICAR, redefinindo prazos já adiados anteriormente. Assim, a universalização da implementação do sistema CAR em todo território nacional, vincula-se as regras do programa de conversão das multas por desmatamento em compromissos de recuperação das áreas afetadas. No entanto, a alteração no Código Florestal pela norma que torna facultativa a inscrição no CAR não contribui para a efetividade desse instrumento de proteção ambiental.

\section{ANÁLISE DA NORMA QUE REGULAMENTA O CADASTRO AMBIENTAL RURAL À LUZ DO CONCEITO DE FAKE LAW}

A expressão fake law deve ser interpretada como algo que tem sentido próprio. Assim como a expressão fake news não comporta uma simples tradução literal, também, a expressão fake law deve ser compreendida semanticamente como palavra com determinado significado que vai muito além de uma simples tradução. $A$ expressão fake law deve ser entendida, no âmbito jurídico, como comando falso, no sentido de enganar o destinatário do ato a ser praticado ou da ação a ser perpetrada. Assim, norma de efeito fake law é a norma instituída com a mera finalidade de falsear o objetivo finalístico da norma, dessa forma, sem qualquer preocupação com os efeitos da incidência da norma no mundo dos fatos, portanto, sem levar em consideração a sua eficácia jurídica e, consequentemente, a sua eficácia social ou efetividade. 
Inicialmente, é preciso atentar para o que significa a possível falta de eficácia jurídica e eficácia social ou efetividade de uma norma de efeito fake law. O termo 'efetividade' ou a expressão 'eficácia social' são adotados em relação ao alcance dos objetivos da norma no mundo dos fatos, sendo impossível verificar tal alcance se não incidir em aspectos próprios da sociologia jurídica. Ainda, usa-se o termo efetividade como sinônimo da expressão "eficácia social", diferenciando-se, assim, da expressão "eficácia jurídica" que, por sua vez, significa aplicabilidade das normas no âmbito jurídico sem a preocupação com a sua efetividade.

Nesse sentido, a distinção entre eficácia jurídica e eficácia social pode ser facilmente compreendida:

\begin{abstract}
A "eficácia" do Direito pode ser vista sob dois prismas. O primeiro, da eficácia social, quando a conduta humana é praticada em observância à norma que é aplicada, ocorrendo a sua "efetividade". Eficácia é a capacidade de a norma alcançar as finalidades estabelecidas. Eficácia jurídica significa a aptidão da norma para gerar efeitos jurídicos, de maior ou menor intensidade, de imediato, às relações jurídicas por ela reguladas e, assim, diz com a sua aplicabilidade, exigibilidade ou executoriedade (PES, 2010, p. 289).
\end{abstract}

Para corroborar com essa explicação é relevante mencionar o que diz José Afonsa da Silva (2007, p. 66) ao afirmar que ao tratar-se "de normas jurídicas, se fala em eficácia social em relação à efetividade, porque o produto final objetivado pela norma se consubstancia no controle social que ela pretende, enquanto a eficácia jurídica é apenas a possibilidade de que isso venha a acontecer". Por isso, a norma pode ter eficácia jurídica e não ter eficácia social ou efetividade. Isso ocorre quando determinada norma em vigor não é observada pela sociedade, mas seus efeitos jurídicos são válidos, como no exemplo de leis que ao serem editadas revogam as anteriores sem que sejam cumpridas no âmbito social.

Nesse contexto apresentam-se as dificuldades de implementação da universalização de dados e acesso a dados exatos da condição dos imóveis rurais no Brasil, conforme demonstra-se a seguir pelo gráfico de informações disponibilizadas pelo Ministério da Agricultura, Pecuária e Abastecimento (BRASIL, 2021): 


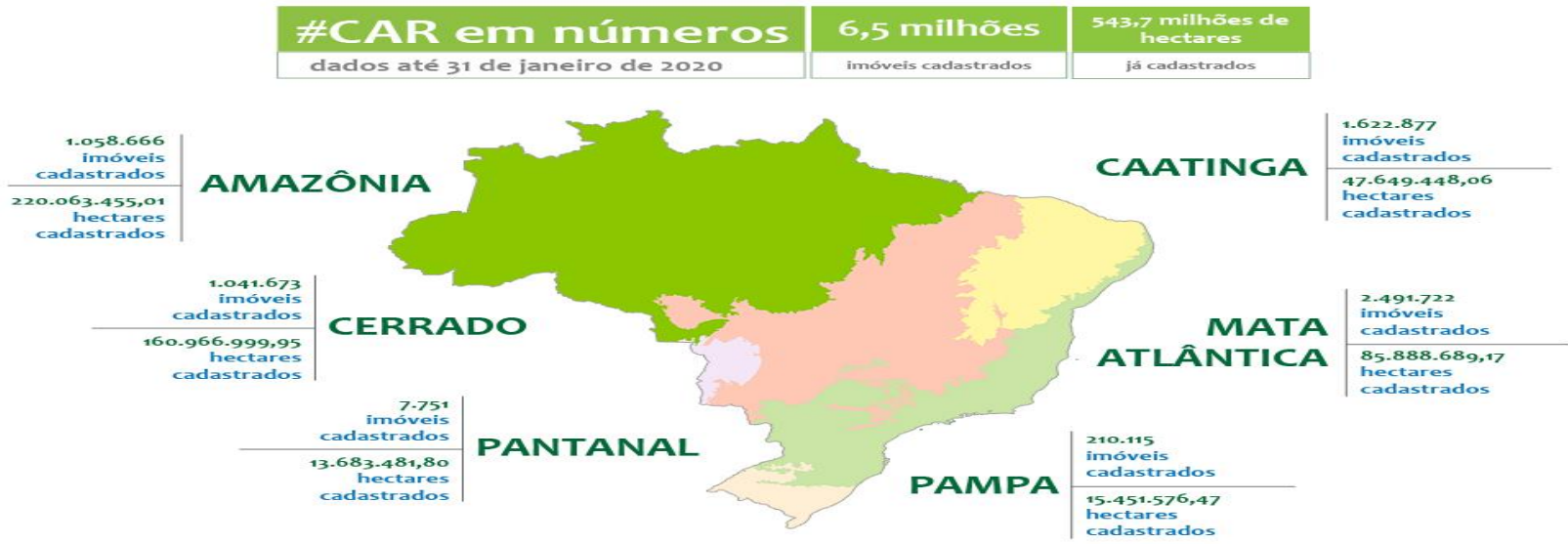

Fonte: Brasil. Ministério da Agricultura, Pecuária e Abastecimento.

O panorama divulgado pelo Ministério da Agricultura, Pecuária e Abastecimento, demonstra a necessidade de universalização dessa política pública, como forma de ampliação das informações ambientais que se revertem em instrumentos preponderantes para gestão ambiental e decisão de adequação de outras ações inseridas na política pública ambiental. Numa comparação simples com os dados do Censo Agropecuário 2017, realizado pelo Instituto Brasileiro de Geografia e Estatística -IBGE, verifica-se que há muitos imóveis rurais no território brasileiro que ainda não foram cadastrados no CAR, é preciso ver que até janeiro de 2021 eram 6,5 milhões de imóveis cadastrados, enquanto os recenseadores do IBGE visitaram 7,5 milhões de endereços rurais entre os dias $1^{\circ}$ de outubro de 2017 e 28 de fevereiro de 2018 (NITAHARA, 2019).

Portanto, definir norma na legislação para tornar facultativa a inscrição dos imóveis rurais no CAR é, no mínimo estranho, diante desses dados e da importância que esse instrumento tem para a implementação de políticas públicas ambientais.

Assim, é necessário analisar a possibilidade da caracterização de fake law. Uma norma fake law é a norma elaborada com o objetivo de ludibriar a totalidade dos destinatários das normas jurídicas ou de alguns setores, tais como um determinado setor econômico ou social, sem a preocupação com os efeitos concretos, sem considerar a efetividade dos comandos normativos, ou seja, sem considerar a eficácia social. Quanto à eficácia jurídica, a norma fake law tem a sua validade assegurada enquanto não for desvendado o seu teor de falsidade, de 
enganação ou de ludibriação, ou seja, enquanto persistir o efeito fake law a norma será tratada como válida. A norma fake law perderá a sua validade, enquanto norma jurídica, assim que desvendado esse efeito de engano, de comando normativo falso, com a revogação da norma ou com a declaração de inconstitucionalidade ou, ainda, no caso de medida provisória, com o fim de sua vigência após o transcurso do prazo máximo de validade.

Um dos maiores impasses vincula-se as diversas prorrogações para implementação do sistema CAR, com a universalidade de informações sobre os imóveis rurais no âmbito do território nacional. O Decreto n. 8.439 , de 29 de abril de 2015, delegou a competência ao Ministério do Meio Ambiente para a prorrogação de mais prazo, nos termos estabelecidos no art. 29, $\S 3^{\circ}$, e art. $59, \S 2^{\circ}$, da Lei n.12.651/2012. Com base nesse decreto, o Ministério do Meio Ambiente baixou a Portaria MMA n. 100, publicada no DOU no dia 5 de maio de 2015, prorrogando o prazo para a inscrição de proprietários rurais ao Sistema de Cadastro Ambiental Rural por mais 1 ano.

O Vice-Presidente da República, através da Lei n. 13.295, de 14 de junho de 2016, prorrogou, novamente, o prazo para a inscrição no CAR até o dia 31 de dezembro de 2017, permitindo, por sua vez, a prorrogação por mais 1 ano, alterando assim os arts. 29 e 78-A da Lei n. 12.651/2012.

Em 2016, a Lei $n^{\circ} 13.335$ estabeleceu como prazo para adesão ao PRA o mesmo prazo de inscrição no Cadastro Ambiental Rural (CAR), 31 de dezembro de 2017 (prorrogado sucessivamente até 31 de maio de 2018, pelo Decreto 9.257/2017, e 31 de dezembro de 2018, pelo Decreto 9.395/2018). A inscrição no CAR não teve mais seu prazo prorrogado até surgir a norma fake law que tornou facultativa uma obrigação fundamental.

A Medida Provisória no 884, de 14 de junho de 2019, convertida na Lei no 13.887/2020, é a norma de efeito fake law que alterou o Código Florestal para tornar a inscrição no Cadastro Ambiental Rural - CAR uma faculdade para os proprietários de imóveis rurais. A Medida Provisória no 884/2019 por ter sido convertida em lei mantém em vigor a norma com o efeito fake law, que somente será desvendado no 
dia em que for declarada a sua inconstitucionalidade ou revogada a regra que torna facultativa a inscrição antes obrigatória no Cadastro Ambiental Rural - CAR.

É preciso ressaltar que o Código Florestal, Lei nำ12.651, de 25 de maio de 2012, criou um dos mais importantes instrumentos de proteção ao meio ambiente que é o Cadastro Ambiental Rural, obrigatório para todos os imóveis rurais, com a finalidade de integrar as informações ambientais das propriedades e posses rurais, compondo base de dados para controle, monitoramento, planejamento ambiental e econômico e combate ao desmatamento, fixando um prazo determinado para que todos os imóveis rurais fossem inscritos. No entanto, a Medida Provisória no 884/2019 alterou essa regra ao dispor que o prazo da obrigatoriedade de inscrição dos imóveis rurais passa a ser por tempo indeterminado, ou seja, deixa de ser obrigatório.

A indefinição no prazo final para implementação do sistema CAR, descortina realidades e dificuldades de implementação dos sistemas de gestão ambiental no Brasil, reduzindo o grau de informações sobre as áreas rurais e suas respectivas condições ambientais.

Essa regra jurídica de efeito fake law, de iniciativa do Poder Executivo ao ser convertida em Lei teve a anuência do Poder Legislativo a partir da significativa representação da bancada ruralista, com a clara intenção de atender os interesses do setor econômico do agronegócio sem a mínima preocupação com a efetividade da norma alterada.

Portanto, essa norma fake law que torna facultativa a inscrição no CAR é similar ao placebo utilizado como medicamento que não exerce nenhum efeito concreto sobre o paciente, provocando apenas efeito psicológico. Pois, o objetivo do CAR é viabilizar o Sistema Nacional de Informação sobre Meio Ambiente - SINIMA, para promover a identificação e integração das informações ambientais das propriedades e posses rurais, instituindo base de dados para subsidiar 0 planejamento ambiental, o controle e monitoramento de importantes espaços ambientais e, sobretudo, auxiliar nos processos de proteção do meio ambiente e de regularização ambiental. Portanto, o Cadastro Ambiental Rural da forma como está disposto, a partir das mudanças, via norma fake law, deixa de ter efetividade no 
mundo dos fatos. É norma que agrada setores descompromissados com a tutela do meio ambiente e, por isso, requer o desvelar de seu efeito fake law para que o CAR volte a ser tratado como um instrumento viável para a proteção do meio ambiente.

\section{CONCLUSÃO}

Após a análise de alguns elementos que integram o conceito do que se denomina de fake law, verifica-se que normas com esse efeito tem como objetivo apenas agradar alguns setores sociais e, ao mesmo tempo, ludibriar a totalidade dos destinatários da norma, dando entender que se trata de norma válida, eficaz juridicamente, mas que a qualquer tempo pode ter desvendada a sua intenção de não produzir qualquer eficácia social ou efetividade concreta. A norma fake law é similar ao placebo utilizado como medicamento que não exerce nenhum efeito concreto sobre o paciente, provocando apenas efeito psicológico. Assim, a norma de efeito fake law tem como objetivo, não expresso, mas sordidamente velado, atender interesses não republicanos, que não estão claros no texto legislativo, no sentido de dar a entender que se está diante de uma norma válida e eficaz.

A resposta ao problema formulado inicialmente de verificar se é possível a identificação de efeito fake law na alteração legislativa do Código Florestal para tornar facultativa a inscrição no Cadastro Ambiental Rural - CAR, é no sentido de apontar que, inequivocamente, está presente esse efeito de tornar a legislação de proteção ambiental ineficaz socialmente ou inefetiva, adotada apenas para agradar determinado setor econômico.

Portanto, é necessário desvendar essa norma de efeito fake law, com a sua revogação ou a declaração de inconstitucionalidade, para que a inscrição de imóveis rurais junto ao Cadastro Ambiental Rural volte a ser obrigatória e, consequentemente, esse instrumento possa ser usado como política pública de controle e gestão ambiental para que o resultado seja a tutela administrativa efetiva do meio ambiente.

\section{REFERÊNCIAS}

Brasil. Ministério da Agricultura, Pecuária e Abastecimento. Serviço Florestal Brasileiro. Números do CAR, Brasília - DF, 07 de abril de 2021. Disponível em: 
https://www.florestal.gov.br/index.php?option=com_content\&view=article\&id=77\&cati $d=61 \&$ Itemid=264. Acesso em 27 set. 2021.

BRASIL. Lei 12.651 de 25 de maio de 2012. Dispõe sobre a proteção da vegetação nativa. Disponível em: http://www.planalto.gov.br/ccivil_03/_ato20112014/2012/lei/l12651.htm. Acesso em 29 set. 2021.

GIDDENS, Antony. As Consequências da Modernidade Tradução de Raul Fiker. São Paulo: Unesp., 1991.

LEITE, Jose Rubens Morato; AYALA, Patryck de Araújo. Direito ambiental na sociedade de risco. 2. ed. Rio de Janeiro: Forense Universitária, 2004.

MACHADO, Paulo Afonso Leme. Direito ambiental brasileiro. 21. ed. São Paulo: Malheiros, 2013.

MUNDIM, Cristiano Pacheco de Deus. Cadastro Ambiental Rural - CAR: originalidade, inovação ou mera burocracia. Revista de Direito Agrário e Agroambiental. Brasília. v. 2, n. 1, p. 152 - 167, Jan/Jun. 2016.

NITAHARA, Akemi. Censo Agropecuário: Brasil tem 5 milhões de estabelecimentos rurais. Rio de Janeiro, Agência Brasil, Publicado em 25/10/2019. Disponível em: https://agenciabrasil.ebc.com.br/geral/noticia/2019-10/censo-agropecuario-brasiltem-5-milhoes-de-estabelecimentos-rurais. Acesso em 29 ago. 2021.

PES, João Hélio Ferreira. A efetividade da ação popular e de instrumentos similares na tutela dos bens ambientais do Brasil e Portugal. In MOSCON, Cledi de Fátima Manica. Temas de Direito Público: Justiça e Administração Pública (org.). Porto Alegre: Editora Nuria Frabris, 2010.

SCHIER, Adriana da Costa Ricardo. Direito Administrativo Social em prol da realização do direito fundamental ao desenvolvimento. In: Direito Administrativo, Políticas Públicas e Estado Sustentável. Organizadores: Adriana da Costa Ricardo Schier; Caroline Müller Bitencourt, Curitiba: İthala, 2020.

SILVA, José Afonso da. Aplicabilidade das normas constitucionais. $7^{a}$ ed., São Paulo: Malheiros, 2007. 